\title{
DINÂMICA E CONSUBSTANCIALIDADE DAS RELAÇÕES SOCIAIS*
}

\author{
DANIÈLE KERGOAT \\ TRADUÇÃo DE ANTONIA MALTA CAMPos ${ }^{1}$
}

\begin{abstract}
RESUMO
Conflitos de classe, de gênero e raciais tendem a ser concebidos, interpretados e enfrentados isoladamente. A autora analisa desenvolvimentos no campo dos estudos feministas e da sociologia do trabalho que apontam para a interdependência dessas categorias sociais, tanto no plano teórico como na prática de movimentos sociais de mulheres e trabalhadoras.
\end{abstract}

PALAVRAS-CHAVE: Relações sociais; classe; gênero; raça; consubstancialidade.

\section{ABSTRACT}

Class, gender and racial conflicts are often thought of, interpreted and handled as isolated. The author presents developments in feminist and labor studies which suggest the interdependency of these social categories, theoretically and in the political practices of women's and worker's social movements.

KEYWORDS: Social relations; class; gender; race; consubstantiality.

[*] Este artigo é uma versão revista e ampliada da conferência apresentada no dia 8 de setembro de 2006 na sessão "Pensar o intricamento dos sistemas de dominação: gênero, classe e raça" do $11^{\circ}$ Congresso da Associação Francesa de Sociologia (AFS), em Bordeaux.

[1] Revisão técnica de Helena Hirata.

[2] Vale acresentar que a experiência que vivi como militante feminista e sindicalista tornou impossível para mim separar ou hierarquizar os efeitos das relações de classe e de gênero.
Desde os anos de 1970-1980² mobilizo os conceitos de consubstancialidade e coextensividade para procurar compreender de maneira não mecânica as práticas sociais de homens e mulheres frente à divisão social do trabalho em sua tripla dimensão: de classe, de gênero e origem (Norte/Sul). Tais práticas não se deixam apreender por noções geométricas como imbricação, adição, intersecção e multiposicionalidade - elas são móveis, ambíguas e ambivalentes. No entanto, não basta afirmar que compreendemos a sociedade em termos de relações sociais - é preciso antes definir tais relações, e suas propriedades. Utilizando as metáforas de "círculo" e "espiral", procurarei esclarecer minha maneira de apreender os fenômenos sociais a partir de uma perspectiva materialista, histórica e dinâmica, e retomarei às definições de consubstancialidade das relações sociais e sua propriedade essencial: a coextensividade. No presente artigo, procuro responder às seguintes questões: O que é uma relação social? Quais são suas propriedades? Porqueéheuristicamente proveitoso apreender as práticas sociais em termos de relações sociais? Como o fazer, concretamente? 
Uma relação social é uma relação antagônica entre dois grupos sociais, instaurada em torno de uma disputa [enjeu]. É uma relação de produção material e ideal3: Colette Guillaumin mostrou, por exemplo, que a "racialização" é a construção ideológica e discursiva da natureza dos dominados, a "face mental" e cognitiva dos vínculos materiais de poder. Toda relação social é, assim, uma relação conflituosa.

Tomemos o paradoxo das relações sociais de sexo: simultaneamente à melhora da situação da mulher, em particular no mercado de trabalho, ocorre a persistência, às vezes mesmo a intensificação, da divisão sexual do trabalho. "Tudo muda, mas tudo permanece igual". Esse paradoxo me parece bastante ilustrativo dos impasses que um tipo de pensamento que segmenta as relações sociais, que os considera isoladamente, enfrenta. A minha tese, no entanto, é: as relações sociais são consubstanciais ${ }^{4}$; elas formam um nó que não pode ser desatado no nível das práticas sociais, mas apenas na perspectiva da análise sociológica; e as relações sociais são coextensivas: ao se desenvolverem, as relações sociais de classe, gênero e "raça"' s se reproduzem e se co-produzem mutuamente.

Voltemos ao paradoxo. A participação da mulher no mercado de trabalho aumenta, mas as segmentações, horizontais e verticais, entre empregos masculinos e femininos, perduram. As desigualdades de salário persistem, e as mulheres continuam a assumir o trabalho doméstico. A meu ver, no entanto, isso não representa nenhuma aporia ou contradição interna às relações sociais de sexo, mas aponta para o fato de que o capitalismo tem necessidade de uma mão-de-obra flexível, que empenhe cada vez mais sua subjetividade: o trabalho doméstico assumido pelas mulheres libera os homens e, para as mulheres de alta renda, há a possibilidade de externalização do trabalho doméstico para outras mulheres.

Assim, não se pode argumentar no âmbito de uma única relação social. O suposto paradoxo aponta para a imbricação, na própria gênese da divisão sexual do trabalho produtivo e reprodutivo, de diferentes relações sociais, e de relações sociais que não podem ser abordadas da mesma maneira.

Tomemos um outro exemplo da análise das propriedades das relações sociais: o sentimento de muitas mulheres, e em particular de muitas mulheres jovens, de que a igualdade está garantida ou pode ser realizada rapidamente, de que o sucesso profissional é possível e a divisão das tarefas é um problema de negociação entre os indivíduos que compõem um casal, uma questão de simples "boa vontade". Este sentimento é evidentemente paradoxal, pois ele não corresponde à realidade, tal como a vivenciamos, tampouco corresponde às estatís-
[3] Godelier, Maurice.L'idéeletle matériel: pensée, économies, sociétés. Paris, Fayard, 1982 .

[4] O termo, emprestado da teologia, não deve gerar confusão: ele é utilizado aqui em sua acepção mais trivial, de "unidade de substância". Falar em consubstancialidade sugere que a diferenciação dos tipos de relações sociais é uma operação por vezes necessária à sociologia, mas que é analítica e não pode ser aplicada inadvertidamente à análise das práticas sociais concretas.

[5] O termo "raça" é utilizado aqui da mesma forma que classe ou sexo, isto é, como categoria socialmente construída, resultado de discriminação e produção ideológica (Guillaumin, Colette. L'idéologie raciste. Paris: Gallimard, 2002 [1972] [col. "Folio Essais"]). Dada a carga social e histórica da palavra, no entanto, utilizarei-a entre aspas. Tal solução não é totalmente convincente, mas os debates não conduziram ainda ao estabelecimento de uma alternativa teorica e ideologicamente consensual entre os sociólogos. Portanto, faço aqui um uso estratégico da palavra raça, apontando para um conceito politico, cultural e social, que evidentemente não deve ser tomado no sentido biológico. 
[6] Isso pode ser explicado pelo fato de que, na consciência coletiva, a igualdade não é mais uma utopia mobilizadora, mas um estereótipo, um cliché. $\mathrm{E}$ isso não é recente: cf. os trabalhos de Jean Kellerhals ("Ambiguités normatives de l'échange conjugal: le problème de la norme d'équité". Revue Suisse de Sociologie, 1981, vol. 7, n ${ }^{\circ}$ 3, pp. 311-327) sobre a norma igualitária.

[7] Em um grande número de sociedades, ocorre uma reorganização das relações entre os sexos. Encontramos um bom panorama disso em artigo de Mens, Yann. "Europe, Chine, Moyen-Orient, Afrique: famille, le grand chambardement", <http:// www.alternatives-internationales.fr/ article.php3?id_article $=330$ \%.

[8] Para a diferenciação destas três noções remeto a Dunezat, Xavier. Chômage et action collective. Luttes dans la lutte: mouvements de chômeurs et chômeuses de 1997-1998 en Bretagne et rapports sociaux de sexe. Versailles: tese de doutorado, UVSQ, 2004, pp.111ss.

[9] Em outro campo,odas jogadoras de futebol profissionais, Christine Mennesson demonstrou que as práticas inovadoras que não ultrapassam o nível das relações sociais podem questionar as relações sociais de sexo, mas não as colocam realmente em perigo. Cf. Mennesson. Etre une femme dansle monde des hommes: socialisation sportive et construction du genre. Paris, L'Harmattan, 2005.

[10] Godolier, op. cit. ticas ${ }^{6}$. Essa ilusão vem do fato de que tanto especialistas como leigos freqüentemente misturam dois níveis distintos de realidade, o das relações intersubjetivas e o das relações sociais. As relações intersubjetivas são próprias dos indivíduos concretos entre os quais se estabelecem. As relações sociais, por sua vez, são abstratas e opõem grupos sociais em torno de uma disputa [enjeu].

A distinção entre relação intersubjetiva e relação social permite compreender que, se a situação mudou de fato em matéria de relações intersubjetivas entre os sexos e nos casais 7 , as relações sociais, porém, continuam a operar e a se manifestar sob suas três formas canônicas: exploração, dominação e opressão8 (que podem ser ilustradas pelas diferenças salariais, pela maior vulnerabilidade e maior risco de ser vítima de violências). Ou seja, se de um lado há um deslocamento das linhas de tensão, de outro, as relações sociais de sexo permanecem intactas 9 . Da mesma maneira, são as práticas sociais - e não as relações intersubjetivas - que podem dar origem a formas de resistência eque podem, portanto, ser as portadoras de um potencial de mudança no nível das relações sociais. O exemplo da Coordination Infirmière, movimento social do fim da década de 1980 na França,é esclarecedor. Nas reuniões do movimento, o convívio era inegavelmente feminino: as integrantes faziam questão de chamar-se pelo nome, perguntar sobre a saúde, comentar uma roupa nova ou uma ida ao cabeleireiro etc. São formas de relação intersubjetiva que suavizam o clima das reuniões, mas que não afetam de maneira alguma a dinâmica da dominação masculina no interior do movimento. Assim que uma disputa surgia no horizonte, os velhos mecanismos voltavam ao seu lugar (por exemplo: quem falará à imprensa?). O que pode de fato questionar as relações sociais de sexo são as práticas sociais coletivas: por exemplo, decisões como quais as mulheres que terão as responsabilidades formais (presidência da associação) e práticas (responsabilidades organizacionais durante as manifestações), ou a decisão de que haja um aprendizado coletivo em situações de fala diante de um público etc.

Não é por serem mulheres que as enfermeiras são subversivas quanto à relação social de sexo - vemos com este exemplo que o sujeito das lutas não se justapõe ao sujeito da dominação —, mas sim porque se transformaram em um sujeito coletivo produtor de sentido e sujeito de sua própria história. Elas saíram da imagem imposta de feminilidade para se tornarem mulheres portadoras de poder de ação na construção e no desenvolvimento das relações sociais. Por meio delas, o grupo social "mulheres" apropriou-se de outras maneiras de pensar e agir, de outras formas de "produção social da existência humana" ${ }^{10}$.

Da mesma maneira, quando realizava uma pesquisa sobre trabalhadoras, eu procurava explicitar que, com o termo "trabalhadoras", não buscava apenas "mulheres", mas tampouco "trabalhadores". Por 
isso, evitei naturalizar a expressão "mulheres trabalhadoras". Ao contrário, tentei mostrar como elas se inscreviam de maneira original nas relações sociais de sexo, assim como nas relações de classe. O problema era mostrar como elas muitas vezes se constituíam, em suas lutas, como sujeitos coletivos de sua própria história, sujeito completamente original em suas práticas, e como sujeito sempre em transformação e irredutível a uma única categoria.

\section{RELAÇÕES SOCIAIS E CATEGORIZAÇÃO: RELAÇÃO COMPLEXA}

O problema da categorização é inerente a qualquer atividade que consista em analisar o entrecruzamento de relações sociais. Este tema, assim como o da universalidade e da intersecção das relações, éum dos problemas centrais com os quais se confrontam os estudos pós-coloniais e o feminismo negro (blackfeminism).

O cruzamento das categorias de "raça"/gênero/classe não é uma novidade na tradição francesa. Sem termos que voltar a Flora Tristan - o que seria, de qualquer forma, proveitoso para tratar de nossa questão - , podemos notar um bom número de trabalhos que não precisaram se valer dos estudos pós-coloniais ou do feminismo negro para insistir no entrelaçamento entre dominações. As divisões decorrentes da desigualdade de classe, de sexo e de pertencimento a um grupo étnico eram reconhecidas em certos meios de militância e por alguns trabalhos acadêmicos: vale lembrar o colóquio internacional organizado em 1987 pelo Atelier Production et Repreoduction ${ }^{11}$ sobre as relações sociais de sexo, e as afirmações e demonstrações de que "a classe era dotada de gênero" e de que "o gênero era dotado de classe"; os estudos sobre a divisão sexual do trabalho que insistiram na necessidade de cruzar as relações de gênero com as relações de classe e com a relação Norte/Sul; ou ainda, evidentemente, os trabalhos de Colette Guillaumin ${ }^{12}$ que propuseram uma análise dos processos ideológicos recorrentes de naturalização do sexo e da "raça".

Mas esses trabalhos ainda eram minoria. Além disso, tais entrecruzamentos de desigualdades foram antes objeto de alusões que de análises aprofundadas: nesses estudos, classe e "raça" eram associadas, mas sem que para tanto fosse preciso dar centralidade a tal imbricação. Assim, apesar das promissoras teorizações marxistas dos anos de 1980, poucos estudos dedicaram-se, em termos de relações de gênero, às práticas de mulheres das classes populares ${ }^{13}$, enquanto, metodologicamente, a "família" permaneceu (e ainda permanece) associada àquelas das classes médias e altas, sendo evidente que as configurações familiares não são da mesma ordem para uma mulher da burguesia e para uma mulher de classe popular ${ }^{14}$.
[11] Collectif APRE. Les rapports sociaux de sexe: problématiques, méthodologies, champs d'analyse. Paris: Iresco, 1988.

[12] Guillaumin, op.cit.

\footnotetext{
[13] Evidentemente há exceções: ver por exemplo os trabalhos de Armelle Testenoire ("Eloignés au quotidien et ensemble: arrangements conjugaux en milieu populaire". Cahiers du Gen$\left.r e, 2006, \mathrm{n}^{\circ} 41\right)$.

[14] E para uma mulher de "minorias raciais" e para uma mulher "branca". Mas isto começa a ser estudado graças à consideração da "raça" em trabalhos recentes, em particular de jovens pesquisadore(a)s.
} 
[15] O fim da sociedade de classes tradicional não permite a resolução do impasse sobre as relações de classe. Estas vêm se exacerbando, não mais graças ao movimento operário como no período glorioso entre 1945 e 1974, mas em virtude das classes dirigentes. Um único indicador desta exacerbação: a evolução das taxas de pobreza, publicada pelo Insee em julho de 2007. Durante 2005 (último ano disponível), a taxa de pobreza passou de $11,7 \%$ a $12,1 \%$ : $260 \mathrm{mil}$ pessoas se tornaram pobres. Trata-se de um agravamento sensivel, pois é o maior aumento desde que existem tais estatísticas.

[16] Morrison, Toni. "Luttes de classes et pauvreté plus tabous que le racisme". Entrevue avec Gie Gorris. MO* Magazine, 6/02/2007. Trad. francesa Edith Rubinstein. <http:/ sisyphe.org/article.php3 ?id__article $=2625$, acessado em o1/03/2007.

[17] Hooks, Bell. Feminist thery: from margin to center. Boston: South end Press, 1981.

[18] Poderíamos utilizar igualmente o exemplo daquilo que Rhacel Parrenas Salazar (Servants of globalisation: women, migration and domestic work. Standford, California: Standford University Press, 2001) chamou de "mobilidade de classe contraditória". Este conceito considera, por número de imigradas, a simultaneidade da experiência de desqualificação social e da ascenção na hierarquia econômica em relação às pessoas deixadas no país de origem e às condições econômicas vividas anteriormente.

[19] Hill, Collins. Black feminist thought: knowledge, conciousness and the politics of empowerment. Londres: Harper, 1990.

[20] Combahee River Collective. "Déclaration du Combahee River Collective". In: Falquet e outros (coords.). (Ré)articulation des rapports sociaux de sexe, classe et "race". Repères historiques et contemporains. Paris: Université (Cahiers du Cedref), 2006; Davis, Angela. Femmes, race et classe.Paris/Nova York: Des Femmes/ Random House, 1983 [1981].
O impasse a respeito das classes sociais não desapareceu. Na França, como em outros lugares, as disputas e os antagonismos de classe vêm se aprofundando ${ }^{15}$. É certo que os estudos feministas invocam regularmente a necessidade do cruzamento entre gênero, "raça" e classe. No entanto, o cruzamento privilegiado é entre "raça" e gênero, enquanto a referência à classe social não passa muitas vezes de uma citação obrigatória. É interessante notar que essa minimização dos conflitos de classe se verifica também nos Estados Unidos. Em entrevista recente, Toni Morrison, pouco suspeita de ser indiferente aos problemas de "raça" e gênero, afirmou que "por trás das tensões raciais nos Estados Unidos, se esconde, na realidade, um conflito entre classes sociais - [que] é um tabu muito maior do que o racismo" ${ }^{16}$.

$\mathrm{Na}$ França, a estrutura da cena militante e política é tal que poucos homens e mulheres de grupos dominados, ou com origem em tais grupos, podem fazer-se ouvir. No caso do feminismo negro, no entanto, muitos dos estudos foram realizados por mulheres negras, freqüentemente oriundas de meios populares. Foi o que as permitiu avançar em conceitos como o de "dupla consciência" (double consciousness) ${ }^{17}$, que procura compreender o caso de trabalhadoras domésticas negras e seu duplo posicionamento, de proximidade e distância, em relação ao "poder branco"18 e, de modo mais geral à noção de interlocking syste$m s^{19}$, que procura compreender o entrelaçamento entre os sistemas de classe, raça e sexo.

Essa origem de classe (classe sexual, classe social, classe étnica)é determinante na compreensão da gênese e do desenvolvimento desses conflitos. Em particular, tem como conseqüência a percepção da "raça" como uma possível modalidade de experiência de classe, pois, ao trazer a experiência e o sujeito para o centro das análises, permite a passagem do problema da dominação pura para o problema das resistências, da revolta e da emergência dos movimentos sociais ${ }^{20}$. Tais trabalho anglófonos não trazem uma novidade radical, no entanto; eles apenas abrem a possibilidade de atualização e visibilidade para teorias e conceitos que se encontravam marginalizados no campo acadêmico e, dessa forma, o enriquecimento dos estudos feministas.

Apesar de estes trabalhos oferecerem grandes contribuições para o campo de investigação, isso não significa que devamos acatar sem cautela seus conceitos centrais: a racialização dos antagonismos de classe nos Estados Unidos, por exemplo, não pode nos fazer subestimar os conflitos em outros países, como a França. Tomarei aqui o exemplo da noção de interseccionalidade, que atualmente se tornou uma espécie de "receita". A interseccionalidade, para retomar a definição de Kimberlé Crenshaw em seu artigo "Mapping the margins", refere-se à "maneira como o posicionamento das mulheres negras, na intersecção de raça e gênero, torna sua experiência concreta da violência conjugal, 
da violência sexual e das medidas para remediá-las qualitativamente diferente da experiência concreta das mulheres brancas" ${ }^{21}$. Trata-se portanto de apreender a variedade das interações das relações de gênero e de "raça", o mais próximo possível da realidade concreta das mulheres afro-americanas. O próprio título do artigo ["Mapeamento das margens"] é um resumo da crítica que faço a ele: pensar em termos de cartografia nos leva a naturalizar as categorias analíticas. Elsa Dorlin antecipou essa crítica:

[...] a definição [de Crenshaw] das relações sociais como setores de intervenção implica que as mulheres [...] que enfrentam mais do que uma discriminação se acham em setores isolados. [...] O conceito de interseccionalidade e, de maneira geral, a idéia de intersecção, dificulta pensar uma relação de dominação móvel e historicamente determinada [...]. Em outros termos, a interseccionalidade é um instrumento de análise que coloca as relações em posições fixas, que divide as mobilizações em setores, exatamente da mesma maneira pela qual o discurso dominante naturaliza e enquadra os sujeitos em identidades previamente definidas ${ }^{22}$.

Dito de outra forma, a multiplicidade de categorias mascara as relações sociais. Ora, não podemos dissociar as categorias das relações sociais dentro das quais foram construídas. Assim, trabalhar com categorias, mesmo que reformuladas em termos de intersecções, implica correr o risco de tornar invisíveis alguns pontos que podem tanto revelar os aspectos mais fortes da dominação como sugerir estratégias de resistência. A noção de multiposicionalidade apresenta, portanto, um problema, pois não há propriamente "posições" ou, mais especificamente, estas não são fixas; por estarem inseridas em relações dinâmicas, estão em perpétua evolução e renegociação.

Os estudos pós-coloniais e o feminismo negro tiveram de fato o mérito de desconstruir o pseudo universalismo das grande teorias, de apresentar o problema da heterogeneidade do grupo das mulheres e também de colocar radicalmente em questão as noções de solidariedade e fraternidade. É este o sentido da reflexão de Audre Lorde ${ }^{23}$, que insiste na importância da noção de "diferenças" como "catalisadores" da mudança social e critica a confusão freqüente entre a "necessidade de união e a necessidade de homogeneidade". Em um outro registro, são os trabalhos de bell hooks que chegam à questão: São as diferenças que levam a uma experiência feminina compartilhada? Ou a luta contra o sexismo é suficiente para unificar a classe das mulheres? Enfim, é suficiente falar somente de diferenças e antagonismos entre as mulheres, ou é o próprio gênero que, construído diferentemente segundo posições de classe e de raça, é questionado 24 ?
[21] Crenshaw, Kimberlé Williams. "Mapping the margins: intersectionality, identity politics, and violence against women of color". In: Fineman, Martha Albertson e Mykitiuk, Rixanne (eds.), The public nature of private violence. Nova York, Routledge, 1994, pp. 93-118.

[22] Dorlin, Elsa. "De l'usage épistémologique et politique des catégories de 'sexe' et de 'race' dans les études sur le genre". Cahiers du Genre, 2005 , $\mathrm{n}^{\circ}$ 39, pp. 83-105, pp. 92-93.

[23] Lorde, Audre. "Age, race, class and sex: women redefining difference". Trabalho apresentado no Colloque de Copeland. Amherst: Amherst College, 1980.

[24] Para uma exposição exaustiva dos trabalhos norte-americanos que discutem a questão da fragmentação do grupo das mulheres e seu questionamento como classe distinta, cf. Juteau, Danielle. "De la fragmentation à l'unité: vers l'articulation des rapports sociaux". In: L'ethnicité et ses frontières. Montréal: Les Presses de l'Université de Montréal, 1999. 
[25] É por isso que não falo aqui de relações sociais de idade/geração. Estas não aparecem como relações de produção no que concerneà nossa sociedade, embora possa ser o caso para outras sociedades.
Tais questões são evidentemente cruciais - e poderíamos nos referir também, nesse contexto, a grupos de classes sociais ou a grupos racializados. É certo que, colocadas desta maneira, em termos de "ou isso/ou aquilo", elas parecem levar a um impasse. Colocar o problema nos termos da consubstancialidade das relações sociais permite uma outra abordagem: de acordo com uma configuração dada de relações sociais, o gênero (ou a classe, a raça) será - ou não será - unificador. Mas ele não é em si fonte de antagonismo ou solidariedade. Nenhuma relação social é primordial ou tem prioridade sobre outra. Ou seja, não há contradições principais e contradições secundárias. Quando as mulheres da rede hoteleira Accor enfrentam conflitos, o fazem como mulheres, trabalhadoras, mulheres negras; não fazem reivindicações separadas. Lutando dessa maneira, elas combatem a superexploração de todos e todas e sua luta, assim, tem alcance universal.

Essa abordagem exige o esclarecimento de alguns princípios, se não quisermos confundir práticas sociais, relações sociais e identidade, e se não quisermos que a idéia de consubstancialidade seja usada em todo e qualquer registro e se torne, por assim dizer, um saco de gatos.

\section{ALGUNS PRINCÍPIOS DE UTILIZAÇÃO DA NOÇÃO DE RELAÇÕES SOCIAIS}

O objetivo é, portanto, desnaturalizar radicalmente as construções que se baseiam na diferenciação das desigualdades, sem com isso perder de vista a dimensão concreta das relações sociais. Essa análise vai contra a idéia de que, por exemplo, as relações de classe se inscrevem unicamente na instância econômica, e as relações patriarcais, unicamente na instância ideológica. Cada um desses sistemas possui suas próprias instâncias, que exploram economicamente, dominam e oprimem. Estas instâncias articulam-se entre si, de maneira intra e intersistêmica. Tal enunciado lança um desafio à análise empírica. Como não isolar as relações sociais, se não quisermos trabalhar com categorias reificadas? Para esboçar uma resposta a esta questão, enumero a seguir alguns princípios e proponho algumas orientações metodológicas.

Em primeiro lugar, um imperativo materialista: essas relações gênero, "raça", classe - são relações de produção25. Nelas, entrecruzam-se exploração, dominação e opressão. É indispensável analisar minuciosamente como se dá a apropriação do trabalho de um grupo por outro, o que nos obriga a voltar às disputas (materiais e ideológicas) das relações sociais. Por exemplo, no que concerne às relações sociais de sexo, tais disputas são formadas pela divisão do trabalho entre os sexos e o controle social da sexualidade e da função reprodutiva das mulheres. 
Em seguida, um imperativo histórico: o caráter dinâmico das relações sociais é central para a análise. Elas devem ser historicizadas, pois possuem uma estrutura que permite sua permanência, mas também passam por transformações que correspondem a períodos históricos e a eventos que podem acelerar seu curso. No entanto, não se deve jamais historicizar uma relação social em detrimento de outras. Isso significaria transformar a relação em categorias caracterizadas pela metaestabilidade.

O terceiro imperativo: definir as invariantes nos princípios de funcionamento das relações sociais. Por exemplo, a divisão sexual do trabalho: suas formas são extremamente instáveis no tempo e no espaço, mas isso não afeta o fato de que há dois princípios organizadores - o princípio da separação (o trabalho do homemé distinto do trabalho da mulher) e o princípio da hierarquia (o trabalho do homem "vale" mais do que o trabalho da mulher) ${ }^{26}$.

Por fim, devemos estar atentos à maneira como os dominados reinterpretam e subvertem as categorias: isso impede sua reificação. Porém, a subversão só pesa sobre as relações sociais se for coletiva.

Voltemos aos conceitos de consubstancialidade e coextensividade. A idéia de consubstancialidade, como espero ter mostrado, não implica que tudo está vinculado a tudo; implica apenas uma forma de leitura da realidade social. É o entrecruzamento dinâmico e complexo do conjunto de relações sociais, cada uma imprimindo sua marca nas outras, ajustando-se às outras e construindo-se de maneira recíproca. Como disse Roland Pfefferkorn, "essas relações estão envolvidas intrinsecamente umas com as outras. Elas interagem e estruturam, assim, a totalidade do campo social" 27.

Mas o fato de as relações sociais formarem um sistema não exclui a existência de contradições entre elas: não há uma relação circular; a metáfora da espiral serve para dar conta do fato de que a realidade não se fecha em si mesma. Portanto, não se trata de fazer um tour de todas as relações sociais envolvidas, uma a uma, mas de enxergar os entrecruzamentos e as interpenetrações que formam um "nó" no seio de uma individualidade ou um grupo.

Quanto à coextensividade, ela aponta para o dinamismo das relações sociais. O conceito procura dar conta do fato de que as elas se produzem mutuamente. Para ilustrar esse ponto, utilizarei exemplos retirados dos trabalhos da rede temática "Gênero, classe, raça: relações sociais e a produção da alteridade" 28 da Associação Francesa de Sociologia (AFS).

Os trabalhos de Stéphanie Gallioz ${ }^{29}$ a respeito do uso da mão-de-obra feminina na construção civil mostram a emergência do estereótipo do que a autora chama de "a mulher civilizadora", à qual opomos o homem selvagem, bruto e semi-analfabeto. Vemos bem como este estereótipo leva às relações sociais de sexo. Mas ve-
[26] Kergoat, Danièle. "Division sexuelle du travail et rapports sociaux de sexe". In: Dictionnaire critique du féminisme. Paris: PUF, zooo, pp. 35-44 [Trad. bras. in Dicionário crítico do feminismo. Hirata, Helena (org.). São Paulo, Editora da Unesp, 2009].

[27] Pfefferkorn, Roland. Inégalités et rapports sociaux: rapports de classes, rapports de sexes. Paris, La Dispute, 2007 (col. Le Genre du Monde). 
[30] Hamel, Christelle. L'intrication des rapports sociaux de sexe, de "race", d'âge et de classe: ses effets sur la gestion des risques d'infection par le VIH chez les français descendant de migrants $d u$ Maghreb. Paris: tese de doutorado, EHESS, 2003, p. 643.

[31] Dussuet, Annie. Travaux de femmes: enquêtes sur les services à domicile. Paris: L'Harmattan, 2005.
[32] Scrinzi, Francesca. "'Ma culture dans laquelle elle travaille': les migrantes dans les services domestiques en Italie et en France". Cahiers $d u$ Cedref, $\mathrm{n}^{\circ} 10$, pp. 137-162, p. 141.
[33] Idem. Les migrant (e)s dans les emplois domestiques en France et en Italie: construction sociale de la relation de service au croisement des rapports sociaux de sexe, de race et de classe. Nice: tese de doutorado, Université Nice Sophia Antipolis, 2005, p.339. mos igualmente como, ao mesmo tempo, e mantenhamos em mente as altas taxas de imigrantes na construção civil, tal imagem reforça as relações sociais racializadas/racializantes. Além disso, tal fato está de acordo com as relações entre capital e trabalho.

Christelle Hamel mostra como os efeitos do gênero e do racismo se conjugam e se reforçam mutuamente na construção identitária e na sexualidade juvenil. A respeito de algumas jovens descendentes do Maghreb, ela nota

[... o quanto a organização das relações sociais de "raça" reforça as relações sociais de sexo - o que cria uma incompreensão entre estas jovens e seus pais, aquelas idealizando a vivência da sexualidade na sociedade francesa enquanto estes desenvolvem um sexismo identitário, de onde emerge um controle crescente -, e o quanto as relações de sexo reforçam as relações sociais de idade e de classe: a fuga do controle parental, muito mais visivel entre as jovens que os jovens, perturba sua trajetória escolar e as leva a sair de casa prematuramente, o que conduz a uma situação de precariedade, em que as relações de sexo são ainda mais acentuadas"3o.

Os trabalhos de Annie Dussuet ${ }^{31}$ a respeito dos serviços a domicílio vão em direção semelhante. Ela mostra como as relações de gênero permitem que a exploração econômica se intensifique: o sistema de gênero gera um tipo de exploração suplementar, pois o envolvimento subjetivo dos assalariados, parte fundamental do trabalho, não é reconhecido, pois não é objeto de uma formação institucionalizada, nem remunerado, pois não está previsto explicitamente no contrato de trabalho, sendo as tarefas materiais as únicas tarefas descritas. Nesse caso, o gênero cria a classe.

Porfim, Francesca Scrinzi mostrou que, além das relações de classe e sexo, "as relações de trabalho no setor de serviços reforçam e reproduzem categorias [...] racistas e dão origem a uma estrtura de hierarquização social estabelecida sobre uma base "racial"32. Em sua tese, ela mostra que no trabalho de assalariados do setor comercial, não há simplesmente reprodução dos estereótipos dominantes, mas também a produção de novas formas de expressão e funcionamento do racismo. Segundo os empregadores do setor, estas mulheres (imigrantes, trabalhadoras do setor de serviços)

[... ] não possuem senso de organização, nem a racionalidade necessária para o trabalho; apesar disso, elas são humanas, alegres e sólidas, fortes [...]. A apreciação dos trabalhadores imigrantes coloca em cena a oposição entre racionalidade moderna do trabalho em nossa sociedade e o sentimento, a corporalidade, o instinto e as qualidades eminentemente encarnadas por estes 33 . 
Ela mostra igualmente como a condição ligada às relações de raça provoca o cruzamento das fronteiras de gênero34. Inversamente, por múltiplos exemplos, Scrinzi mostra a maneira pela qual as relações de sexo, e a determinação de gênero que elas supõem, podem racializar os trabalhadores migrantes, e, inversamente, como essa racialização reorganiza as relações de sexo.

\section{UM PARADIGMA: O TRABALHO DE CARE}

Este imbricamento, este dinamismo, esta co-produção das relações sociais de classe, gênero e "raça" podem ser encontrados de maneira paradigmática no trabalho de care35. De fato, esta forma de trabalho profissional renovou-se nas últimas décadas sob o efeito conjugado da crescente taxa de atividade das mulheres nos países ocidentais, do envolvimento cada vez maior no trabalho profissional e, porfim, do aumento dos fluxos migratórios (em particular femininos) do Sul para o Norte e do Leste para o Oeste. Esses fenômenos tiveram como efeito a externalização crescente do trabalho doméstico.

O trabalho de care encontra-se no cruzamento das relações de classe, sexo e "raça". Eleé um instrumento precioso para observar a evolução dessas relações: (1) radicalização e extensão qualitativa e quantitativa das relações de classe entre uma nova classe servil (a nova classe operária não-industrial) e as novas mulheres empregadoras ${ }^{6}$ : irrupção de uma oposição de classe pela primeira vez direta - e não mais mediada pelos homens (pais, maridos, amantes) — entre as mulheres que vêem seus capitais econômico, social e cultural aumentarem e as mulheres, francesase estrangeiras, cadavez mais numerosas, quevêem sua situação se precarizar e sua renda diminuir. Trata-se da aparição de novas formas de relação de classe com a aparição e o desenvolvimento de uma nova classe trabalhadora, não industrial, fortemente feminina e feminizada, e o número crescente de empregadores. (2) Evolução da relação entre os sexos, por conta deste trabalho doméstico superexplorado que não resolve em nada os problemas do trabalho doméstico (problemas não considerados pelas sociedades ocidentais), apenas os desloca. (3) Evolução das relações sociais de "raça": vemos a racialização do trabalho de care através da naturalização das qualidades que seriam próprias a esta ou aquela etnia; além disso, essas novas relações estão no coração das famílias, por intermédio da babá, da empregada doméstica ou da cuidadora dos membros idosos da família. O outro, o estrangeiro, não está mais somente nas periferias das grandes cidades ou nas cidades satélite. Ele/ela vive e trabalha no seio mesmo das famílias que, há não muito tempo, não eram atingidas por este fenômeno migratório. A "alterização" - construção ideológica da figura do "outro" - e a racialização tomam formas inéditas. (4) Aparição
[34] Ibidem, p. 286.

[35] Kergoat. "Rapports sociaux et division du travail entre les sexes". In: Maruani, M. (dir.), Femmes, genre et sociétée. Paris, La Découverte, 2005 , pp. 94-101 (col.L'État des Savoirs).

[36] Sobre este ponto, cf. Rollins, Judith. "Entre femmes: les domestiques et leurs patronnes". Actes de la Recherche en Sciences Sociales, $1990, \mathrm{n}^{\circ}$ 84 , set. 
Recebido para publicação

em 7 de janeiro de 2010 .

\section{NOVOS ESTUDOS}

CEBRAP

86 , março 2010

pp. $93-103$ de novas formas de concorrência entre, de um lado, os trabalhadores e trabalhadoras dos países do Sul e do Leste, e, de outro, o número crescente de trabalhadores dos países ocidentais em situação de precariedade. Ambos vivem em situações economicamentee/ou legalmente precárias, mas de formas diferentes.

Por meio deste exemplo, vemos bem como as três relações são inseparáveis e não somente se reforçam, mas se co-produzem mutuamente: a relação de classe reforçada pelos processos de naturalização, de racialização e de "generização" do trabalho de care; a racialização, à qual os empregos domésticos estão particularmente sujeitos, reforça e legitima a precarização (e, portanto, as relações de classe) e a "generização"; a relação de gênero exacerba a relação de classe na medida em que a feminização dessas últimas é um fenômeno novo para o corpo social e, portanto, para o qual ainda não há uma resposta, e reforça as relações de raça pela sua naturalização.

No entanto, trabalhadores e trabalhadoras do setor de care não formam uma categoria estável, apesar da importância do trabalho do setor de care para as sociedades ocidentais.

Compreender melhor as relações sociais e seu entrelaçamento, analisá-las e elaborar um método para pensá-las, é dar um passo em direção à sua superação. Recusar-se a pensar por idéias e categorias fixas (raciocínio que leva a aporias em termos de ação política, como vimos - cf.os debates sobre o uso do véu islâmico) permite recolocar no centro da análise o sujeito político (e não a vítima de múltiplas dominações), levando em consideração todas as suas práticas, freqüentemente ambíguas e ambivalentes.

Trata-se de um esforço para pensar - e para fornecer um método para pensar - tanto a pluralidade dos regimes de poder como a alquimia que transforma, em mais ou menos longo prazo, esta dominação interiorizada em práticas de resistência.É, portanto, um método para detectar os germes de utopia na realidade social contemporânea.

DANiÈLE KERGOAT é socióloga, diretora emérita de pesquisa no CNRS - Centre Nacional de la Recherche Scientifique. Paris 8-Paris 10. 